\title{
Looking through dementia: what do commercial stock images tell us about aging and cognitive decline?
}

\author{
Kevin Harvey \\ University of Nottingham \\ Gavin Brookes \\ Lancaster University
}

\begin{abstract}
Commercial stock images are existing, artificially-constructed visuals used by businesses and media outlets to articulate certain values, assumptions and beliefs. Despite their pervasiveness and accessibility, little is known about the ways in which stock images communicate meanings relating to health and illness. This study examines a broad range of common stock images which depict dementia and aging, revealing the tendency for older people with dementia to be represented in objectifying and de-humanising terms emphasizing disease and deficit at the expense of the whole person, while precluding any possibility of enduring personhood. As well as introducing a multimodal critical discourse approach which can be adopted by other researchers examining the ideological underpinnings of health and illness imagery, this study underscores the importance of critically interrogating stock photography - a much neglected, yet profoundly influential, cultural resource that can shape the ways we think about and respond to illness and disease.
\end{abstract}

\section{Keywords}

Dementia; Aging; Multimodal Critical Discourse Analysis; Visual communication; Stock images; Getty 


\section{Introduction}

In recent decades, qualitative health research has become increasingly occupied with analysing the discursive and textual dynamics of health and illness (Lupton, 1992; Gwyn, 2002). Most of this work has focused on the linguistic content of the texts being analysed, often at the expense of exploring their non-linguistic, particularly visual, elements such as pictures, photographs, illustrations, etc. This mono-modal perspective has been fruitful for analyses of texts in which language is the primary (or only) mode of communication, such as patient records and transcripts of healthcare interactions. However, nowadays many genres of communication, including websites, print media, advertising and public health information, draw upon health-related discourses (that is, attitudes, ideas, assumptions, values to do with health) in decidedly multimodal ways, relying not only on language, but a combination of semiotic resources, including visual images, fonts, layouts and sounds (Machin \& van Leeuwen, 2007). It is important, therefore, to interrogate such multi-semiotic forms of communication since, as well as being highly pervasive, they are, as Harrison (2002) rightly argues, subtly able to naturalize and reproduce certain versions of reality, or otherwise 'provide us with views of how things should be' (2002: 857). Thus, at a time when communication is increasingly turning from words to images - to the extent that visual images now routinely permeate our lives (Martin, 2015) - there is a growing need for qualitative health research to engage with methods more finely attuned to identifying and systematically critiquing health-related discourse that manifests not only in language, but across these different modes of communication.

To the best of our knowledge, our study is the first of its kind to examine critically the visual discourses surrounding a topical health concern, dementia, in a large sample of stock images sourced from a leading commercial image bank. Our analysis sets out to critique these images, elucidating the dementia- and age- related discourses that are conveyed by them and 
which inform their design. This study thus offers a timely response to the need for more research which explores the visual discourse surrounding dementia in communication in the public sphere. At the methodological level, we set out to demonstrate how methods from multimodal critical discourse analysis (Kress \& van Leeuwen, 2001, 2006; Machin, 2007, 2013; Machin \& Mayr, 2012) can enhance the analysis of visual health communication by providing predictable and adaptable tools for describing and critically examining texts beyond the linguistic level. We also aim to demonstrate the potential of stock images - as a form of visual media that is all-too-often overlooked and taken at face-value by researchers to artfully and emphatically convey particular discourses about health and illness - discourses which, due to their pervasiveness in contemporary public communication, have the capacity to shape perceptions and understandings of health-related topics for the public at large.

We begin by introducing multimodal critical discourse analysis, providing an overview of its origins, assumptions and applications in qualitative health research to-date. We then consider commercial stock images as a source of qualitative health data, before introducing our topic of study, dementia. The methodology section describes how we sourced the stock images in our data and provides a more detailed overview of the specific concepts and tools from multimodal critical discourse analysis which we draw on in our analysis. Following this, we report our analytical findings by describing, in rich, qualitative detail, the visual discourses that surround dementia across our sample of stock images. As part of this analysis, we will also consider the dementia- and age- related ideas, values and identities that are both expressly and implicitly articulated by these visual resources. The article concludes with a discussion of the main findings and by reviewing the utility of multimodal critical discourse analysis as a method for exploring and critiquing (visual) health-related discourses, not only in stock imagery, but across all genres of contemporary visual communication. 


\section{Background}

\section{Multimodal critical discourse analysis}

Any introduction to multimodal critical discourse analysis should begin with the body of approaches from which it originates, namely critical discourse analysis. With its origins in linguistics, critical discourse analysis is a theoretical perspective concerned with the ways in which ideology, power and inequality are enacted, reproduced and challenged through discourse (Fairclough, 1989, 1995; Reisigl \& Wodak, 2001). On a practical level, this usually involves closely analysing texts in terms of the linguistic choices that inform their design, with the aim of showing how those choices foreground certain kinds of ideas, values and identities while backgrounding or concealing others (Fairclough, 2003). These communicative choices are then interpreted and related to the wider contexts in which the texts in question were produced and consumed in order to understand why the texts were designed in that way and to consider how they might influence and be influenced by the societies in which they originated (van Dijk, 2001).

As our introduction suggests, critical studies of discourse originally focussed only on the linguistic choices made in the creation of texts. The application of multimodality to this area of study came later and was initiated by the work of linguists Gunther Kress and Theo van Leeuwen (Kress \& van Leeuwen, 2001). Amongst other things, this work brought about two important considerations for critical discourse studies: (1) that texts create meaning through combinations of communicative modes which include language, but, for many texts, also images, color, fonts, layouts and sound; and (2) that communication, partly as a result of technological developments, is becoming increasingly multimodal. Taking these observations as a starting point, Kress and van Leeuwen developed a series of analytical concepts that 
would better enable scholars working within critical discourse studies to describe and explain the role that modes other than language play in texts (Machin, 2007).

The majority of critical studies of health discourse have adopted a decidedly monomodal perspective, focussing on the ways that issues like power, ideology and inequality both shape and are shaped by language used in health-related contexts. As well as reflecting the linguistic bias of critical discourse studies generally, this tendency towards mono-modality also reflects the penchant for such studies to take as their data texts that are characteristically mono-modal or at least which feature language as their primary mode, for example interactions between patients and practitioners (Wodak, 1996, 1997; Ziółkowska, 2009), interviews (Galasiński, 2008), emails (Harvey, 2012), online support groups (Brookes, fc) and suicide notes (Galasiński, 2017). Given their aims and the primacy of language in the texts they analysed, the implementation of mono-modal, linguistic approaches in such studies was not only justified, but also fruitful for their analyses.

Offering something of a counterweight to this mono-modal tradition, a small but growing number of studies have adopted multimodal analytic approaches to explore the relationship between health and issues such as power and ideology in texts that are characteristically multimodal in their design - making use not only of language, but also resources like image, font, layout and so forth. For example, Koteyko and Nerlich (2007) analysed the multimodal discourse of online probiotic advertising. Thompson (2012) adopted a multimodal critical discourse approach to study visually personalising and responsibilizing discourse in an online mental health community website. Harvey (2013) also adopted multimodal critical discourse analysis to critique the linguistic and visual medicalisation of male baldness in pharmaceutical advertisements for hair loss 'remedies'. Building on this approach, Brookes and Harvey (2015) studied the relationship between multimodal scare tactics and commercial strategies in a diabetes public awareness campaign. Investigating a 
similar topic, Mulderrig (2018) used multimodal critical discourse analysis to examine emotional manipulation and 'nudge tactics' in social marketing produced as part of a UK government public health campaign targeting childhood obesity. Machin and Mayr (2012, pp. 52-56) and Brookes and Harvey (2016) analysed multimodal discourses of commercialisation and privatisation in the websites of UK healthcare providers. Brookes et al. (2016) adopted a multimodal critical discourse approach to compare discourses of babyfeeding in public health texts about bottle and breast feeding. And, finally, in a recent study with more direct relevance to the current research, Brookes et al. (2018) used a multimodal critical discourse approach to explore the linguistic and visual representation of dementia and people with dementia in a small sample of recent (2016) UK press articles.

This body of work reflects a relatively recent but growing interest in multimodality and (critical) health discourse. But more importantly, the insights provided by such studies collectively attest the value of a multimodal critical perspective for elucidating the power of discourse - across a wide variety of text types and on all levels of semiosis - to shape people's understandings and experiences of health and illness. The present study aims to add to this body of work by providing new insights into the visual discourses of dementia, but also aims to expand the reach of multimodal critical discourse analysis in qualitative health research by applying it to an - until now - overlooked and often taken-for-granted textual genre in the form of commercial stock images.

\section{Stock images and image banks}

Image banks, such as Getty Images and Adobe, hold many millions of images and videos which they purchase from photographers, designers, illustrators and film-makers. These images, which mainly consist of 'clichéd photographs of consumer wellbeing or corporate 
achievement' (Frosh, 2008: online), are sold to designers and text producers for a license fee. The stock image industry is large, highly lucrative (worth an estimated $\$ 2$ billion dollars annually) and continues to diversify and expand, competing with traditional photojournalism (ibid.). In this study, we focus on dementia stock images sourced from the industry leader, Getty Images. Founded in Seattle (USA) in 1995 by Irish businessman Mark Getty, Getty Images is now the world's largest supplier of stock images for businesses, consumers and a range of media outlets. It offers a vast - and ever increasing - archive of images, illustrations and film footage which currently totals over 80 million still images and illustrations and more than 50,000 hours of stock film footage. Getty's primary markets are creative industries (including advertisers and graphic designers), the media (print and online), and corporations (e.g. for in-house marketing). Although Getty is based in North America, its reach is global: around half of its revenue is generated outside North America, with customers based in over 50 countries (Machin, 2004: 319). Thus, the images and footage provided by Getty can be found on websites and in advertisements, newspapers, magazines and promotional material across the globe.

The images and films held by image banks like Getty are assigned a series of key words or tags that denote the person, event or thing that the image/footage is designed to represent. These labels refer to a mixture of the tangible things that are depicted in the image/footage, as well as the more abstract concepts that it is designed to represent or the idea or feeling that it is intended to evoke. Image banks are relatively easy to use. Users simply type in a search term reflecting the type of image/footage they are looking for. The website will then display all the images/films that have been assigned tags that match the search term. Depending of course on the specificity of the search term, the number of results generated will vary, but typically reaches tens or hundreds of thousands of images/films. Users can then browse the material displayed, select which image(s) or footage fits their 
purposes and, unless it is freely available, pay online for the rights to use it. From typing in a search term to acquiring a user license, the process of obtaining an image/film from Getty and other image banks is extremely quick and convenient, taking no more than a few minutes.

In this study, we are specifically interested in dementia-related images (photographs, illustrations, and graphics) rather than films. In terms of their content, many of the images that Getty provides depict public figures and significant historical events. However, the most common (and most profitable) types of images are those which do not necessarily depict any specific person or event, but which are designed to convey more abstract concepts or to conjure particular circumstances, ideas or feelings. More often than not, these types of image display professional actors performing a role for the purpose of producing a photograph to be sold to a commercial stock bank. In other words, these abstract images seldom bear witness to any actual event taking place in the world. Yet, these types of image are more commercially appealing to image banks like Getty because they can be purchased for a wider range of uses. Machin (2004: 317) considers the fundamental ways in which this has changed how photographic images are used:

What matters now is no longer only what photographs represent, when and where they were taken, and why. What matters now as much, or more, is how many different contexts they can be inserted into, both in terms of what they represent and in terms of their form, as they must be able to fit into a range of overall layout designs, for instance through colour [sic] coordination. The more they are multi-purpose, generic and decorative, the better they will sell. ${ }^{1}$

Here, Machin (2004) essentially argues that the emphasis on photography has itself switched from one of bearing witness to one of being a symbolic system. He argues that 
this is partly the result of a culture of branding, in which products and services are now represented using images of the ideas, meanings and values (e.g. friendship and romance) that marketeers wish to attach to their wares, rather than the uses or functions of the products and services themselves. It is important to recognize that the symbolic systems that now constitute image banks have not come about by chance but have been actively and intentionally created by large global corporations to suit their commercial needs and interests.

Understanding the socio-political conditions under which stock images are produced for and selected by image banks like Getty is important, since multimodal critical discourse analysis is, as we saw earlier, concerned in no small part with relating discourse to its wider contexts of production and consumption. The commercial drive for abstractness in the production and selection of stock images is significant for this has implications for how complex issues (not least those pertaining to health) are visually represented in these images and, in turn, the vast array of texts - the websites, newspapers, adverts and other publications - in which these resources are regularly used.

\section{Dementia and stock images of dementia}

Dementia is a syndrome encapsulating a range of diseases that cause a series of cognitive impairment symptoms, including problems with memory, reasoning, perception and communication (World Health Organisation (WHO), 2017). The most prevalent type of dementia is Alzheimer's disease, while other variants include vascular dementia, dementia with Lewy bodies and Frontotemporal dementia (Dening \& Sandilyan, 2015). Though all are subsumed under the umbrella term dementia, people experiencing each of these variants are 
likely to present with different symptoms. Even if we set aside this variance across the different strains of dementia, experiences of any dementia will be unique to the individuals affected by it - in other words, the experiences of one person living with Alzheimer's disease are typically distinct from those of another person living with Alzheimer's disease (Clare, 2003; Harman \& Clare, 2006). Dementia is a progressive syndrome, which means that its symptoms are likely to get worse over time. At present, there is no pharmacological cure for dementia. Accordingly, people diagnosed with the syndrome today will still have it when they die.

Dementia, it is said, presents one of the biggest global public health challenges facing the world today: 47.5 million people live with the syndrome worldwide, and there are 7.7 million new cases accruing each year (WHO, 2017). Based on these figures, the total number of people living with dementia is set to rise to 75.6 million in 2030, trebling by 2050 to 135.5 million. In 2016, the British Office of National Statistics (ONS, 2016) published a report showing that dementia had now replaced cancer and heart disease as the leading cause of death in England and Wales, now accounting for over 11 per cent of all deaths registered in 2015.

With no cure in immediate sight, there is a need for research that focuses on people's lived experiences and understandings of dementia in the here and now (Lock, 2013), including how these might be shaped by cultural constructions of the syndrome, for example in the media, public health information and other types of public communication which constitute the primary means through which people routinely access information about, and form their impressions of, dementia (Swinnen \& Schweda, 2015). Indeed, in recent years, it has not been difficult to encounter such constructions in public discourse, not least in the print media, for whom dementia seems to represent an unfailingly newsworthy topic. The media's intense focus on dementia has not gone unnoticed by qualitative health researchers, 
with studies in this area generally reporting the pervasiveness of negative and fear-inducing representations of the syndrome, with common themes including: dementia as an active agent that relentlessly kills people diagnosed with it, dementia as a loss of the self and dementia as social death (Zeilig, 2014; Swinnen \& Schweda, 2015; Brookes et al., 2018). A consequence of this consistently negative and stigmatising representation is that perceptions of dementia amongst the general public are often fraught with fear and misunderstanding (Swaffer, 2014), even though, of course, having dementia does not necessarily mean that the person concerned is demented (Sabat, 2018). Persistently negative media portrayals of dementia are also problematic in the sense that they preclude or downplay the possibility of people 'living well' with the syndrome; indeed, while it is true that dementia can be insufferably distressing for people living with the syndrome and their relatives and carers, this is not necessarily the case all the time, and many people living with dementia continue to lead socially- and physicallyactive lives following diagnosis (Rahman, 2014). Yet, the possibility of living well with dementia in this way is rarely - if ever - suggested by the media's take on the syndrome.

Given the newsworthy nature of dementia, producers of dementia-related texts frequently find cause to delve into the image banks offered by Getty and others in order to furnish their news articles, advertisements and other publications with visuals that are designed to represent and shed light on the syndrome. Machin and Niblock (2006) have argued that the use of stock images in news media has increased over time, with news photographs taking on an increasingly symbolic, rather than descriptive, quality. They attribute this increased reliance on stock imagery to two factors: (1) stock images are cheaper and easier to access than relying on more traditional types of photojournalism (a particularly important consideration for news production companies facing financial and staff cutbacks ${ }^{2}$ ) and (2) with their more symbolic and aesthetic quality, stock images are designed to look good on the page (again, an important consideration at a time when the visual design of 
newspapers and other media is crucial in branding and marketing) (Machin \& Niblock, 2006: 36).

On the other hand, Caple (2013) argues that although stock images are regularly drawn upon in the design of advertising texts, and even the health and lifestyle sections of newspapers, their often-de-contextualized nature means that they are not usually well-suited to the design of news texts. She observes that their use has yet to be become common practice in the production of news discourse, with producers of such texts tending to opt for images that can be tied to a 'discernible news context' (Caple, 2013: 9). While we are sympathetic to this argument and can envisage many types of news stories for which generic stock imagery would be unlikely to be suitable (e.g. about specific people, places or events), we are also of the view that stories about dementia are different in this respect for three main reasons. First, news stories about dementia are rarely stories about specific people, places or events. Rather, with a few exceptions (e.g. stories about celebrities diagnosed with dementia and crimes committed against people with dementia), such reporting usually focuses on less tangible phenomena, such as dementia prevalence patterns, mortality rates and associated risk behaviors. Because these topics do not map so neatly on to any 'discernible news context', as Caple (2013: 9) puts it, they arguably lend themselves more readily to the use of stock images. Second, on a more practical level, stock images of dementia provide text producers with an infinitely more convenient alternative to obtaining photographs of real people living with dementia, which can be difficult to acquire from an ethics perspective. Finally, as a complex syndrome that is often difficult to understand, stock imagery affords the producers of news stories and other texts a useful (but often grossly simplifying) visual short-hand for conveying the complexities of dementia and for helping readers to identify those texts as being 'about' dementia. 
By examining the visual discourse in stock image representations of dementia, our study not only responds to the need for more research which examines public sphere representations of dementia, but also helps to address the general paucity of studies which pay attention to the visual aspects of such representations (a notable exception being the study by Brookes et al. (2018), though this was based on a limited sample of press articles). Stock images should afford a rich source of data through which to explore the visual discourses of dementia, offering broad coverage of the types of visuals that feature prominently across a wide range of contemporary texts.

\section{Data and analytical approach}

\section{Data}

To obtain our data we searched the Getty image bank using the query term 'dementia'. This generated 951 images. We then ranked the images according to 'popularity' (i.e. number of uses) and extracted the top one-hundred images. This sample contained a mixture of photographs, illustrations, brain scans and diagrams. Sourcing the most-used dementia images in this way helps to ensure that our analysis will unpack those visual discourses of dementia which are most prominent and have the widest contemporary reach in terms of audience. It should also be noted that, although dementia features as a search term for all the images in our database, each image has a number of other search terms, which means that they are also likely to be picked up by producers of texts relating to other (though not totally unrelated) topics, such as aging, old age and care. The images in our data feature in a broad range of mass media, mass audience texts, the most common uses being print and online news articles. When they are picked up and used by texts producers, the abstract images 
provided by Getty undergo a process described by Bernstein (1990) as recontextualization that is, they are anchored in particular meanings and interpretations by their contexts and situations of use, including co-occurring modes like captions, accompanying text and other imagery (see also: van Leeuwen, 2008). However, for the purposes of this study we will focus on the original, de-contextualized images, as they would appear to visitors to the Getty website, and thus to users of those images when carrying out their own searches.

\section{Analytical approach}

The approach to multimodal critical discourse analysis we adopt is inspired by the seminal work of Kress and van Leeuwen, introduced earlier, inasmuch as we view the stock images in our data as visual texts culminating from a system of deliberate and motivated design choices made by their producers (Kress \& van Leeuwen, 2001, 2006). Our approach is two-tiered. In the first step, we document the visual choices evident in the design of the stock images in our data. Although Kress and van Leeuwen offer a toolkit for scrutinising choices pertaining to multiple levels of semiosis - including language, image, font, layout, colour and sound (van Leeuwen, 1999, 2005, 2011; Kress \& van Leeuwen, 2001, 2006; Kress, 2010) - this initial step of our approach draws only on those concepts which we deem to be most relevant to the composition of our photographs. Specifically, we examine the visual choices pertaining to the following elements of the stock images:

i.) participants (who is depicted?);

ii.) settings (where are they depicted?);

iii.) gaze (where is the participant(s)' eye gaze directed - do they engage the viewer or other represented participants or look elsewhere?); 
iv.) angle of interaction (from what angle or perspective do we view the participant(s)?)

v.) color (what choices are made in terms of brightness, saturation, purity, differentiation and hue (see Kress \& van Leeuwen, 2006: 232-235))?

Focussing in detail on these questions not only enables us to describe the material composition of the images, but also allows us to begin to interpret the ideological significance of the various representational choices that inform them. Thus, in the second step of our analysis, we interpret these visual choices in terms of the discourses - that is, the dementia- and age- related attitudes, ideas and values - that imbue and are propagated by them. This two-tiered approach broadly corresponds to the Barthian notions of denotation (what is depicted?) and connotation (what is meant or implied?) (Barthes, 1977).

Both authors (linguists with training in discourse analysis) independently analysed all 100 images in the data using the two-tiered approach described above. We then compared our analyses, which were similar, and agreed upon a set of interpretations of the images and dementia discourses. The results of this analysis are reported in the next section.

\section{Analysis}

Of the 100 dementia stock images we obtained from Getty, the majority (seventy-nine) were photographic images of people with dementia (in most cases, actors intended to represent people with dementia). Eleven of the images were either brain scans depicting dementia or photographs of practitioners inspecting brain scans. The remaining ten images were more difficult to categorize; these were more abstract images (including visual metaphors) designed to symbolize, in one way or another, particular aspects of the dementia syndrome. 
In this section we will explore each of these types of image in turn, examining in finer qualitative detail the semiotic choices that are evident in their design. Rather than scrutinize the design choices evident across all the images in our data, we will instead focus here on recurring - and thus highly prominent - features, providing illustrative examples along the way. Although we will address each type of image separately, it is worth bearing in mind that these types of image can often feature side-by-side in their contexts of use, for instance in newspaper articles (Brookes et al., 2018) and, as the forthcoming analysis will show, also draw on many of the same ideologies and assumptions about dementia. Thus, all three types of image - photographs of people with dementia, brain scans and abstract images - can be viewed as drawing upon and perpetuating prominent visual discourses of dementia. Note that, by way of demonstrating the visual discourses explicated in our analysis, we will provide a series of images which we deem to be representative of the broader themes we observed. ${ }^{3}$

\section{Photographs of people with dementia}

The people with dementia in our stock image data are routinely subjected to the processes of objectification and disembodiment. Beginning with the former, Figure 1 below provides an example of the most frequent kind of stock visual representation of dementia or dementia scenario: as the caption suggests, that of an older adult being tended to by a carer or relative. ${ }^{4}$ Here the two participants are situated indoors, in a care home - rather than a private, domestic - setting, both of whom appear against a stark and hazy background that, because of its spartan character, imparts the scene with something of an institutional tone (an impression, in turn, reinforced by the anchoring caption). Although she appears out of focus, and with her back turned towards the camera (for she is not, in this image, the principal focus or subject), the participant performing the role of carer is seen in the act of lightly placing her left hand 
on the older woman's shoulder - a gesture quite clearly of support and what could perhaps also be taken as a sign of consolation.

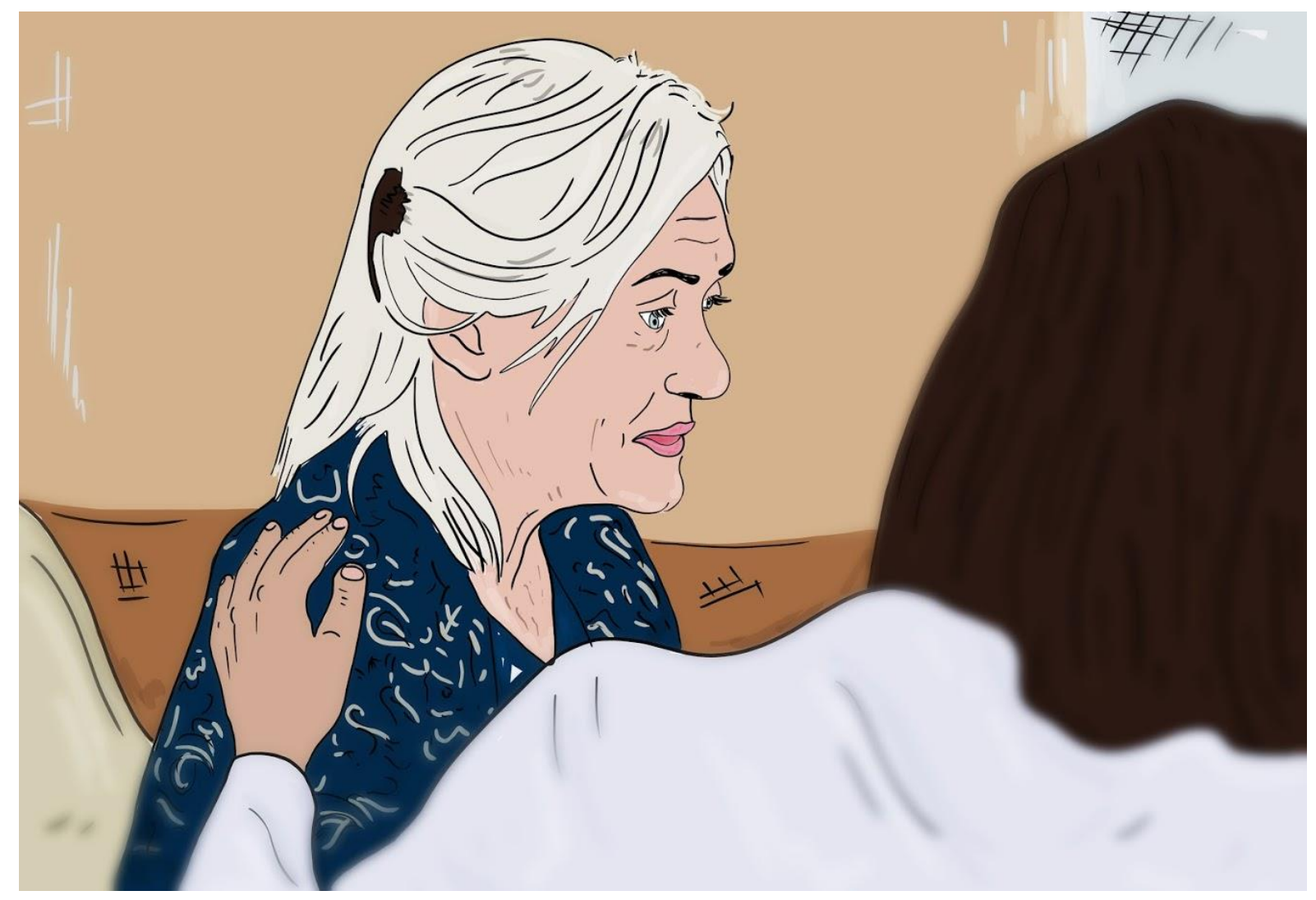

Figure 1. 'Senior woman receiving help in old people's home'.

As is common in these kinds of dementia-care dyads, Figure 1 being no exception, the cognitively impaired participant is presented passively and seemingly rather helplessly depicted here in some kind of listless state of suffering or otherwise fugue of numb despondency. Positioned dominantly in the middle of the frame - the 'pivot around which everything turns' (Kress \& van Leeuwen, 2006: 197) - she is the central presence, standing out in relief such that the viewer's attention is unavoidably drawn towards her - and to the fact that she is seated, inactive, looking out vacantly to an unspecified point outside the frame, without apparent aim or object. Although in the intimate presence of an attentive companion, she neither speaks to nor otherwise interacts with this attending partner. Indeed, 
she appears to be unaware of the presence of the other - at least there is no visual cue in the photograph to suggest the contrary. She is withdrawn and disengaged, appears to be simply passing time by sitting still, performing for the camera the state or condition of 'being blank' (Phinney \& Chesla, 2003), a depiction in keeping with the notion of dementia as disengagement and absence (Swaffer, 2014).

Figure 1 is so composed, moreover, that a negative ('us and them') distance opens up between viewers and the central 'senior' participant. Such an effect is brought about, in no small part, by the image designer's decision to capture her (as someone purportedly with dementia) in a posture where her gaze is averted away from that of the viewer. In this particular 'offer' image (Kress \& van Leeuwen, 2006), the absence of eye contact between us viewers and the woman makes it difficult for us to enter in any kind of symbolic personal relation with her. Since she is not visually addressing us, the woman does not 'demand' anything from us (Kress \& Van Leeuwen, 2006), does not provide us with any indication of how we should symbolically engage with her. We are not, for example, being asked to relate to her - to assume, say, a relation of social affinity with her in the way that a participant actively, knowingly looking out and smiling at us would (if anything, we are forced to adopt the perspective of the caregiver: with the camera positioned behind her we peer over her shoulder to share her view of the person with dementia). Consequently, she appears impersonally, somewhat objectified and removed, as though she were, to quote Kress and van Leeuwen (2006: 119), a specimen 'in a display case', an exhibit offered up for pitying scrutiny (Johnson \& Bytheway, 1999). Yet, at the same time, the fact that she appears in this somewhat objectifying configuration lends the scene a degree of authenticity and makes a 'special claim on our attention' (Synder, 1980: 504). For with her being unaware that she is being looked at, it is as though we, who observe her, have unobtrusively stumbled upon her and her world, while she obliviously goes about her daily business of existing in it (Brookes 
\& Harvey, 2015). This is what you would see if you were there (as carer or onlooker), this is her reality, the picture suggests, for although artificially constructed, it nonetheless purports to be an authentic window on and into the woman's world, a depiction to be taken at face value.

Depicting participants with dementia in such objectifying and somewhat pitiable terms rather than as individuals living purposeful, meaningful lives is a common occurrence in stock dementia photography. It is realized - in extremis - in what we refer to as the disembodied or truncated hands image, a pervasive kind of visual representation that is often used by the press and assorted media outlets to accompany and illustrate stories about aging and dementia. As we have observed elsewhere (Brookes et al., 2018), these particular types of image are highly predictable in composition. The hands so depicted are invariably frail and immobile (even though they are the dominant focus of the camera they perform little action or productive function: they are at rest or else clasped together) in a gesture that, according to Tallis (2013: 119), signifies 'apprehension' and the pointing towards unnamed 'fears for the future'. In Figure 2, for example, we see a pair of hands at rest on a woman's lap, the fingers of her right hand loosely, and perhaps a little anxiously, touching those of her left. While the right hand is somewhat silhouetted against the pastel shades of her dress, the left hand is brightly, clearly lit, to the extent that is easy to pick out granular details in the texture of the skin - features such as wrinkles and creases and even the bones and joints beneath it. The hands, moreover, are tightly framed and rendered in extreme close up - or at least at such a close distance that other parts of the body, including, most significantly, the head, are excluded from view entirely, and therefore we are denied any enlightening access to the person to whom the hands belong.

It hardly needs to be pointed out - by way of recourse to any specialist semiotic framework - that this kind of imagery is blunt and unforgiving - a potent index of fragility 
and decline that communicates an 'unsettling awareness' of the vulnerable materiality of the dementia body (Moran, 2001), a vulnerability which is further emphasized by the fact that we peer down at the hands as from a symbolic position of relative power and superiority (Ledin \& Machin, 2018). Moreover, in symbolically subjecting participants to such extreme levels of objectification, these images undermine - and perhaps even encourage us to question - the 'essential humanity' of people with dementia so depicted (Downs et al., 2006: 236). In fact, pictures like Figure 2 are doubly reductive in that they both literally and figuratively diminish the whole person - literally since what we are directly, 'literally' presented with is an actual fragment of the individual; and figuratively in the sense that this fragment can be interpreted as being symbolically substituted and standing in for the whole person. As with the wellknown medical metonymy whereby patients are depicted and catalogued solely in terms of their ailments or diseases (Segal, 1998: 92), so these participants are transformed and dehumanized to the point where, acutely excised from the frame as they are, it is impossible to personally or meaningfully relate to them. 


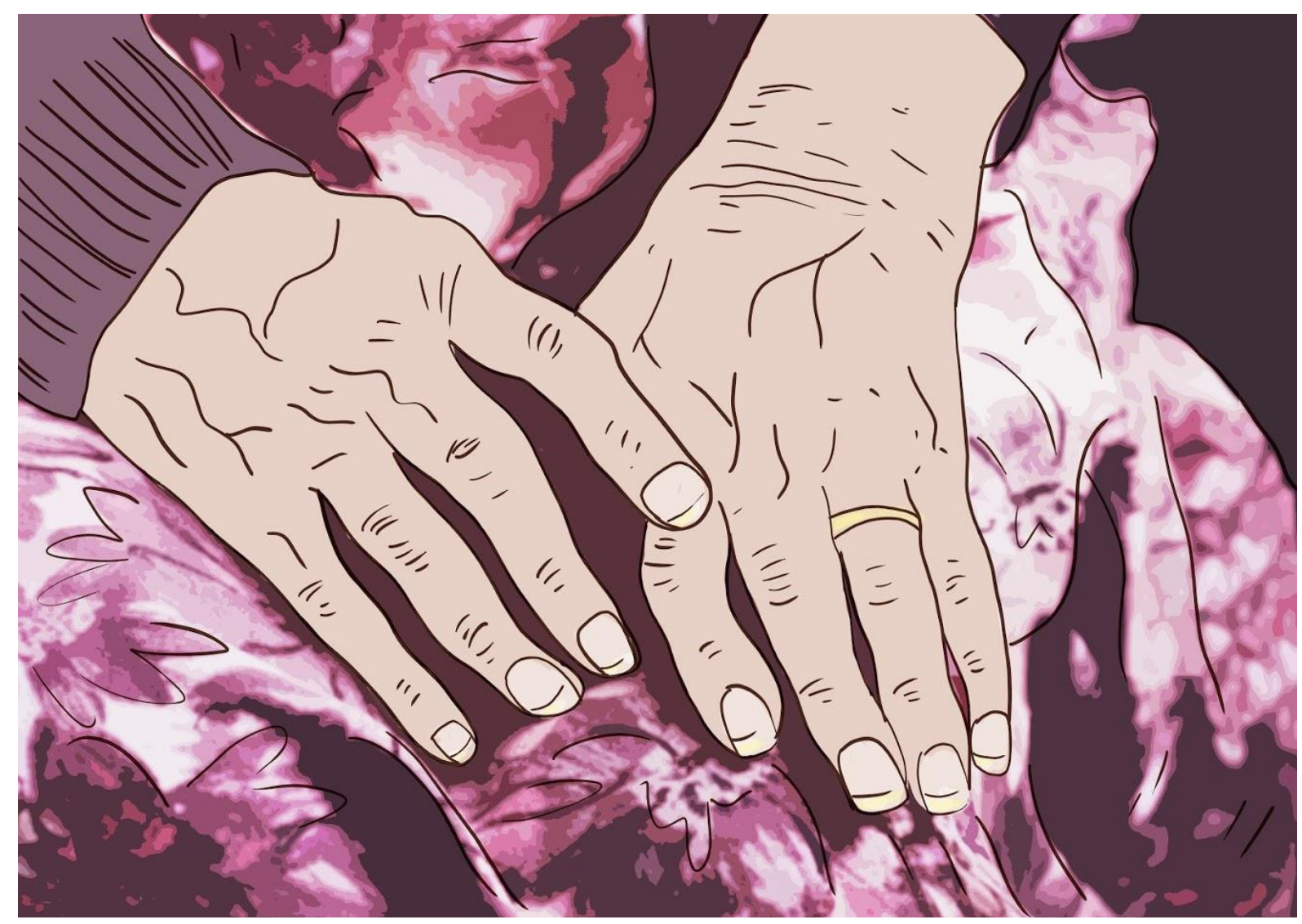

Figure 2. 'Wrinkled old hands'.

Disembodied images such as Figure 2 run the risk of perpetuating the idea, found in much of the medical literature (Kontos, 2006), that dementia is a 'loss of self' (Cohen \& Eisdorfer 2001), a disease that eradicates the wholeness and essence of the individual. Indeed, it is possible to view the reproduction of this kind of disembodied mind-separated-from-body imagery as a type of 'malignant positioning' (Sabat, 2006), that is, an act of visual communication that denies or otherwise undermines the personhood of the individuals so depicted - and, by extension, people with dementia more widely. In his influential book Dementia Reconsidered (1997), Kitwood famously defines personhood as the 'standing or status that is bestowed upon one human being by others' (1997: 8). The personhood of people with dementia, Kitwood argues, is often liable to be undermined through (intentional or otherwise) malignant acts - through processes such as stigmatisation and objectification (i.e. 
treating people as though they were a diseased object or lump of matter) - that emphasize negative attributes and thereby threaten their sense of self-worth (Sabat, 2006: 289).

Accordingly, stock photographs of disembodied hands direct us to see little more than atrophy and depreciation before and instead of the person (Kitwood, 1997). Thus they can be said to constitute what Archer et al. (1983) describe as a species of 'face-ism', that is, images that trade on the assumption that increased facial prominence is commensurate with certain positive human attributes, the head, for example, being the locus of mental life, incorporating facets such as intellect, personality, identity and so forth. Images of nothing but body parts and appendages, therefore, reveal little, if anything, of the character or psychological insight we might have otherwise gleaned from more nuanced and holistic images of people with dementia: certainly in no way, for instance, do they contribute to the person-centred idea that older adults with dementia possess the same value as anyone else and can be 'active agents in their lives', able 'to act on their world' (Downs et al., 2006: 245).

This is not to say that all the stock images offer representations of dementia characterized by depreciation, disease and depersonalisation. Indeed, a number of the photographic images appearing in our dataset offer a more positive take on dementia. For example, in contrast to the general trends we have observed in our foregoing analysis, a minority of the stock images in our data represent people with dementia in less disembodying terms, as physically active and socially engaged with other participants, relatively free of cliché-laden graphics and postures. Take as an example the image reproduced in Figure 3 below. 


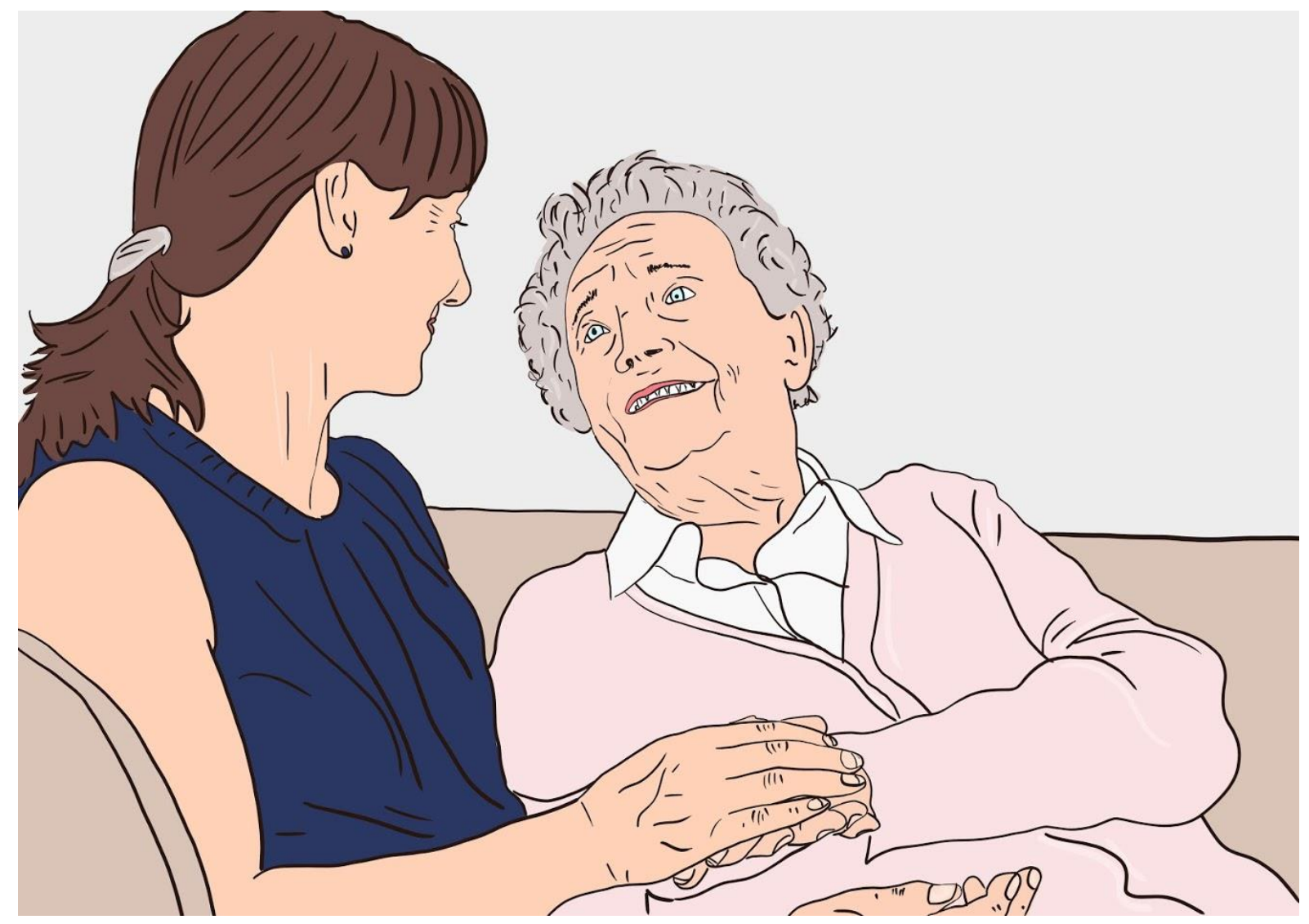

Figure 3. 'Senior woman and caregiver'.

The 'senior woman' shown in this image is depicted in ways that can be contrasted with some of the more commonly reductive visual choices evident in the majority of the photographs in our data. In contrast to the disembodied hands depicted in Figure 2, we are granted a view of this woman's face and most of her body. She is shown as smiling, engaging both visually and physically with the 'caregiver' sitting with her (a far cry from the socially-disengaged participant featured in Figure 1, whose face was emblazoned with an expression of fear and unhappiness and whose gaze was cast out of shot, vaguely directed at something out of reach, situated beyond the scope of the image). However, this kind of depiction in Figure 3 is relatively rare in the context of the photographic images in our data, with photographed participants pictured as visually engaging with either the camera or another participant in just fourteen of seventy-nine images and smiling or laughing in eight of these. Moreover, these 
images, though offering a decidedly more positive visual representation of the person with dementia, still tend to equate living with dementia in terms of dependency and relative inactivity. For example, the caption accompanying the photograph in Figure 3 tells us that the person who the senior woman engages with is her caregiver. Subtle visual choices combine in this image, we argue, to create a symbolic relation between these participants whereby the 'caregiver' is cast in a position of power. Not only is the caregiver positioned higher up in the image relative to the person with dementia - forcing the latter to literally 'look up', in nearawe, to the former - but the caregiver's authority is visually enhanced further by the positioning of her hands which cover and even encase those of the person with dementia (Kress \& van Leeuwen, 2006: 262-264). Thus, so powerful are the discourses of dementia identified over the course of our analysis that they can even be traced - albeit through subtler semiotic means - in images offering an ostensibly more positive representation of the syndrome and people affected by it.

Whether or not they afforded what we might perceive to be more positive depictions of dementia, all the stock images we assessed provide us with little authentic sense of people's personal experiences of dementia, deny us the opportunity of glimpsing any authentic insight into the unique worlds of real people actually living with dementia - since stock images are always produced from an outsider's perspective - and are rarely credible and realistic. The models who appear in them, for example, are typically generic figures or types who, as it were, 'act out' dementia, performances based no doubt on what the image producers concerned stereotypically assume to be the saliently recognisable reality of dementia. We know and learn very little, if anything, about participants in dementia stock images - other than that they tend to suffer and are looked after by others. They are 'destoried individuals' (Eakin, 2004), subjects without any evident personal history, whose voices we never hear, whose perspectives we never share. 


\section{Brain scans}

Intriguingly, pictures of brain scans - whether appearing within an image or constituting it entirely - commonly feature in stock photography. These highly specialized, state-of-the-art visuals encode a range of technical meanings and ideological assumptions, presenting viewers with various interpretative challenges. If conventional photographs possess an 'immediacy and facticity which makes us think that they are real and self-evident' (Featherstone \& Hepworth, 1993: 306), then what claim on our attention do advanced medical imaging techniques make? These technologies have revolutionized the way we perceive the brain and the inside of the body, allowing viewers to picture the invisible (Synder, 1980), to apprehend what cannot be perceived by the naked eye alone (Mitchell, 2015). While the camera makes the outside world around us atomic and manageable (Sontag, 1977), neuroimaging renders 'the space enclosed by the skull' (Beaulieu, 2002: 66) visible and articulable in apparently incontrovertible objective terms. Yet as with conventional photography, which is typically valued for its mimetic quality and hence assumed to carry a ‘burden of truth’ (Barthes, 1977; Taylor, 1992; Newton, 2000), neuroimaging also wields immense rhetorical and persuasive power.

What makes brain scans particularly attractive to stock image producers, and the media outlets who reproduce them, is that they are arguably one of the most widely recognized icons of 'neuroscientific power today' (Pickersgill, 2013: 326), forming a class of so-called expert images which promise to tell us the evident truth about the state and function of the human mind (Dumit, 1999). To see, after all, is to believe. Rather than take neurological images as incontestable reality, however, we consider them to be instances of 'manufactured objectivity', that is, operating to some extent within the same aesthetic and 
technical conventions that shape the reception of other modes of popular scientific imagery (Burri \& Dumit, 2008: 303). Neurological images are at once authoritative and fascinating visually alluring spectacles replete with vivid colors, contours and textures - and their aesthetic quality and hyper-reality afford a unique way of viewing the brain and, by extension, the person. As van Dijck (2011) argues, imaging technologies provide us with more knowledge about health and disease than ever before. Yet, tellingly, they also do a great deal more. Peering inside someone's skull is never an innocent activity, never without ideological consequences, for neurological images 'actually affect our view of the body, the way we look on disease' (2011: 6). Consider, for example, Figure 4, an illustrative example of the various dementia-related stock photographs that feature neuroimaging visuals.

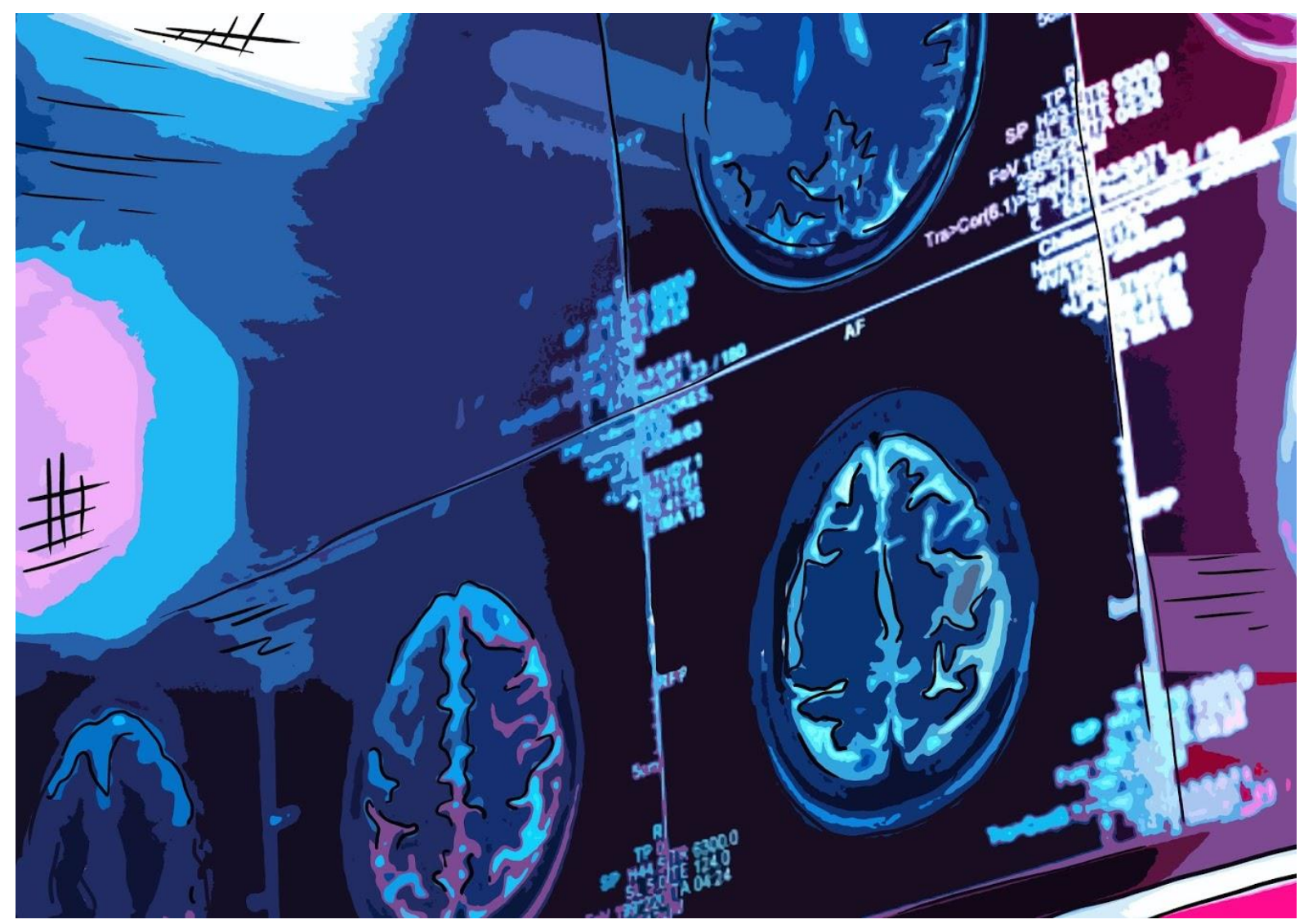

Figure 4. 'Human brain scan in a neurology clinic'. 
The first thing to say about this image is that it is not particularly helpful to the average viewer. What, for instance, are we to make (as non-neurologists) of the series of highresolution brain scans and the technical details (the scales, measurements and so forth) that accompany them? Are we supposed to detect any - if there is any - potential pathology evident in the scans or otherwise make clinical sense of them? Indeed, what exactly are we to take from these highly technical images? From a purely heuristic perspective - accessible as they are only to experts - these neural images are virtually meaningless. Nevertheless, Figure 4 undoubtedly possesses a seductive aesthetic allure and is instinct with certain meanings and associations that will most likely be evident to, and appreciated by, 'ordinary' untrained viewers. In terms of aesthetic appeal, for example, the prominent pink, blue and red light streaks at the far left and right side of the frame imbue the photograph with a highly mannered, ethereal quality (one perhaps at odds with the hyper-reality of the actual scans themselves, for if we were actually present in the photograph, looking directly at neural scans in front of us, we would not of course see them in such a stylized fashion).

Yet at the same time there is no mistaking the fact that Figure 4, for all its aesthetic allure, is an image that powerfully transmits scientific weight and authority, evoking as it does a medical-technical outlook that emphasizes the organic aspect of dementia. If stock photographs of disembodied hands (such as Figure 2) tend to reduce people with dementia to inanimate matter, neural images have not dissimilar ideological consequences: reducing the person with dementia to their (seemingly aberrant) neurobiology. The reproduction and viewing of this kind of stock image makes it difficult to regard dementia as anything other than an organic brain disease - such that, in these strictly neural visual terms at least, the brain can potentially be seen as 'the core of the patient's self' (Zimmermann, 2017: 81). Moreover, rendered in close organic and apparently transparent detail, there is 'something intuitively right' about these bright blue, high-resolution digital brain scans and their apparent 
ability to disclose vital differences between the dysfunctional and normal brain (Dumit 2003, 37). In seeking to make sense of all these neural images, viewers, we argue, might well be led to assume that there are two kinds of brain (and by extension, two types of people): those with and those without dementia. Inevitably, such a category error reinforces the difference between 'normal' people and people with dementia, evincing a segregating 'us' and 'them' dichotomy. Whether intended or not, the reproduction of such technical brain imagery is only likely to reinforce the already prevailing belief that 'everything a person with dementia does and feels is the outcome of brain damage and is abnormal in one way or another' (Sabat, 2014: 108).

\section{Abstract and metaphorical images}

The final recurring kind of stock image we consider takes the form of an abstract or symbolic representation that harnesses - in point of fact evolves around - a key underlying metaphor or symbol. Given the biological, medical and cultural complexity of dementia, and the fact that, as a syndrome, it is widely, popularly misunderstood (Werner, 2003), it is not surprising that such metaphorical images abound in dementia-themed stock photography. Metaphors allow us to talk about one thing in terms of another and are therefore particularly effective at rendering diffuse, intangible or otherwise inexpressibly complex phenomena in vividly arresting and concrete terms. Yet as Lakoff and Johnson (2003) have famously argued, metaphors are never merely descriptive garnish or poetic flourishes but profoundly affect the way we actually see or think about the world. For example, construing the human mind as though it were a machine allows us to understand the systematic nature of thoughts and cognition. At the same time, however, such a trope risks construing the individual as 'broken down' or 'dysfunctional' when disease is perceived to threaten that person's mind 
(Zimmerman, 2017: 73). Metaphors are thus double-edged: they might illuminate and vivify complex entities, but they are simultaneously prone to simplifying and exaggerating them.

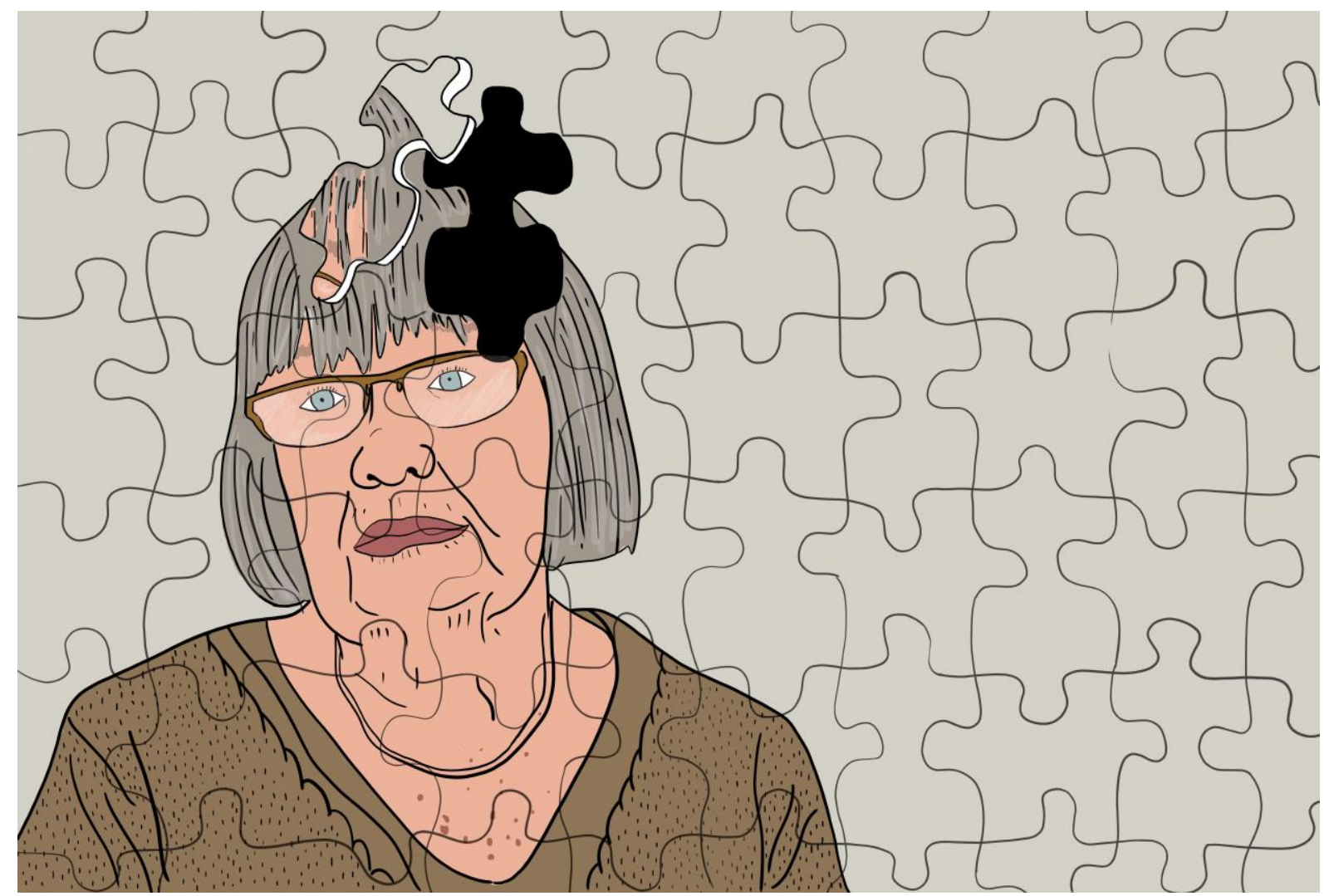

Figure 5. 'Jigsaw puzzle, of a senior woman, falling apart'.

A striking example of this kind of stock metaphorical image is reproduced in Figure 5, a

Photoshop-like illustration that is premised on the idea of dementia and/or the person with dementia as a puzzle. Here we are presented with a medium (head and shoulders) shot of an older woman who is made to appear as though she were compact of a 60-odd piece jigsaw puzzle. Although we see her at a relatively close distance - as Berger (1991) notes, a medium shot signifies a personal relationship between viewer and photographed subject - we are not necessarily aligned with her. She appears at a slightly oblique angle to us (positioned to the left of the frame rather than directly in front of us) and she looks vacantly, obliviously out of the frame rather than return our gaze, thus ruling out any nominal reciprocal social affiliation 
between viewer and subject. Like the 'senior woman' in Figure 1, she is thus presented as 'other' - an impression figuratively reinforced in this case by the conspicuous absence of a prominent piece of the jigsaw: rather than see the woman as whole, the jigsaw satisfactorily completed and intact, what we unavoidably see (indeed this is the most noticeable and telling feature of Figure 5) is a dark cavity in the left side of her head, a carious void signifying absence and decay, the ongoing erosion of the whole person.

Although crude and oversimplifying, the use of the jigsaw motif in dementia imagery is not surprising, in line as it is with other kinds of cultural representations of dementia that associate cognitive impairment with the piecemeal dismantling of the individual. In point of fact, the brain itself - outside of any notion of neuropathology - is often construed in terms of a jigsaw puzzle, a complex organ made up of many intricate pieces that function both independently and harmoniously in order to inform the bigger picture of normal functioning and behavior (Du Plessis, 2011: 6). By this figurative logic, it only takes the absence of one piece of the jigsaw to render it irrevocably faulty - after all, what use and value is a jigsaw puzzle with a central piece missing? - and hence it is difficult not to perceive the woman in Figure 5, metaphorically rendered as she is, as similarly irredeemably deficient, a puzzle that cannot be solved.

Another discernible trope in Figure 5 - though one not so immediately evident but one nonetheless that works in conjunction with the figure of the jigsaw - is the zombie metaphor, namely: the visual depiction of the person with dementia as the 'living dead' (Behuniak, 2011), where dementia can be seen as the 'death that leaves the body behind' (Kitwood, 1997: 3). A number of semiotic elements combine in Figure 5 such that the participant is rendered near zombie-like, a 'non-person' existing principally as corporeal matter (recalling in this sense the truncated hands image in Figure 2). Note, for instance, the seemingly affectless, trance-like state that the woman is in, an impression clearly 
communicated by her vacant, objectless stare, lack of focus, and expressionless mouth, all of which unmistakably suggest that she is lacking cognition and 'devoid of content' (Fontana \& Smith, 1989: 36). Moreover, as we gaze at her, she appears to be actually falling apart before our eyes: not only is a significant piece of her prominently absent - as indicated by the glaring dark hole in the top of her head, the lesion in the brain - but another adjacent jigsaw piece is clearly out place: part of her brow appears incongruously in her crown, suggesting that she is in the process of mutating, transmogrifying into something ultimately unrecognizable (note, too, how some of the joints between the jigsaw pieces appear to be coming loose, as though the wider fabric of the puzzle was becoming warped, beginning to fall apart). In addition, the coordinated use of color and lack of color differentiation - most evidently the predominant use of a muted color spectrum that extends from various shades of beige to overshadowing grey (a weak and ashen palette (Adams \& Osgood, 1973)) contributes to the theme of death and decay: the taupe hues of the women's jumper, hair and remorselessly arid background all chromatically chime with each other, combining to create a lifeless and colorless atmosphere, a gloomy scene of moribundity and deterioration.

Although no doubt arresting, the danger of this kind of death-in-life representation, according to Behuniak (2011: 86), is that it 'delineates between those who are 'afflicted' and the rest of society' and hence 'makes it possible, even justifiable, to socially marginalize those regarded as 'other'.' At any rate, this kind of metaphorical depiction of dementia fails to reach out to viewers with any degree of sensitivity, potentially inviting responses of fear and revulsion rather than empathy and compassion.

\section{Discussion}

Although pervasive, easy to access and reproduce, stock photographs of dementia and aging have received relatively little critical attention from qualitative health researchers (or indeed, 
for that matter, from any strain of communication scholar). This is surprising since such images are a potent and pervasive form of visual communication that subtly reproduce certain values and beliefs surrounding the aging process and therefore have the potential to shape and inform our responses to dementia. Our visual analysis of stock photographs reveals a distinct picture respecting common representations of cognitive decline. A predominant feature of these images is that, in their own unique and various ways, they routinely foreground the biomedical and pathological aspects of aging, emphasizing, in particular, themes such as brain disorder; the (old) age of people living with dementia; the inertia, passivity and vulnerability of such persons, all the while promoting a 'deficit' model of dementia (McGovern, 2011) that reinforces exactly those negative concepts that individuals with the syndrome themselves most emphatically resist (Zimmermann, 2017: 74). Rather than drawing attention to what people with dementia are able to do, and what remains of their cognitive capacities - and thereby adopt a more humanising 'assets' perspective (McGovern, 2011) - these stock images accord with the prevailing narrative of dementia that construes living with the syndrome in terms of ' loss,' 'failure,' and 'meaningless existence', (Harris and Keady, 2008: 7). Indeed, after looking at these images, one could be forgiven for concluding that people with dementia are somehow less than persons (Sabat \& Harré, 1992).

Of course, as our analysis has shown, this is not to say that the only picture of dementia offered by stock images is one of depreciation, disease and depersonalisation, for a number of the images appearing in our dataset offered a more positive take on dementia, with people with dementia depicted as smiling, laughing and visually engaging with other participants. Although such images were relatively uncommon (i.e. eleven of the one-hundred images in our data) and, as we have discussed, often constructed the person with dementia in dependent and relatively disempowered terms, they nevertheless gesture to the possibility of 
representing people with dementia as engaged and indeed socially 'alive' - in sharp contrast to the majority of the images making up our dataset. ${ }^{5}$

In emphasizing the pathological and clinical aspects of dementia, a significant proportion of the stock photographs we have examined convey the idea that the symptoms and progression of dementia are nothing but the outcome of neuropathology caused by disease (Sabat, 2014). Yet, as researchers from a bio-psycho-social (as opposed to a purely biomedical) perspective have shown (see, for example, Kitwood, 1997; Sabat, 2001), the behavior and wellbeing of people with dementia is not only affected by damage to the brain (essential factor though it is of course), but by the social environment in which such people live their lives, including the way in which they are treated by others and how they react to the treatment of others (Sabat, 2014: 108). In other words, dementia is just as much a social and cultural phenomenon as it is a clinical one. Yet stock images appear to articulate only one aspect of the dementia story, privileging a biomedical point of view that is liable to heighten a 'fear-reflex' that, according to Basting (2009: 4), 'is making the experience of dementia worse.' For by predominantly focussing on symptoms of pathology, stock images deny the possibility of health in dementia and older age (Davis, 2004: 372), not to mention the prospect of continued independence or at least some degree of autonomous living (not all people with dementia, of course, are completely dependent on the care of others).

Nevertheless, the ready availability of stock images continues to make them an immensely appealing visual resource to media outlets, with editors often assuming that it is far easier and more economical to access image banks than it is to create or otherwise obtain authentic and bespoke pictures. A recent anecdote offered by an associate of ours exemplifies the point. On asking the editors of a prominent medical publication why, in relation to a feature on dementia and aging, they had drawn upon clichéd stock photographs - images of wrinkly hands, vacant faces, and the like - our associate was informed that acquiring pictures 
of real people in genuine contexts of living would be needlessly time-consuming and impractical. Besides, doing so would potentially entail disrupting the prevailing narrative of dementia-as-decline, one with which average viewers are most likely to be familiar and appreciate. As Devlin et al. (2007: 48) point out, the notion that a reasonable quality of life is still attainable while living with dementia is, in the face of existing negative perceptions of the condition, liable to lack credibility among the general public.

That the media should offer consistently negative portrayals of dementia is hardly surprising, given that research into practices of news production has long observed negativity to be an influential criterion of newsworthiness (Galtung \& Ruge, 1965). It seems reasonable, then, to suggest that there is a demand for negative and clichéd images of aging and dementia among the news media and that stock image producers - as commercial enterprises - are likely to recognize and attempt to respond to this demand in terms of the types of dementiarelated images they produce, hold and distribute every day.

Yet, of course, the danger of media organisations relying on stock images is that their use is only likely to heighten the stigma associated with dementia (Van Gorp \& Vercruysse, 2012; Stites et al., 2018). As Ballenger (2006) observes, the stigma that attends the syndrome issues, in no small part, from the 'anxiety surrounding the boundary between the pathological and the normal' or, to put it another way, dementia's unique 'set of symptoms and behaviors that are judged to deviate from some notion of normal'. Accordingly, the reproduction of stock images that characteristically trade upon the fear of loss of cognition and the erosion of the self are liable to sharpen dementia's already considerable stigma, casting people with the syndrome as 'victims', as though there were no other culturally sanctioned position for them to occupy. It goes without saying, therefore, that both stock photography producers and the media groups and publishers who readily draw on stock images need to reflect more critically on the potential consequences of routinely producing and reproducing visuals that focus on 
deficits at the expense of people's enduring abilities and potentials. There needs to be more positive, more nuanced stock images of dementia in circulation (Gove \& Rohra, 2014), images that emphasize the continuing personhood of people with dementia and their capacity to 'live well' with the syndrome - that is, to lead happy and socially fulfilling lives beyond their diagnoses. A wider repertoire of such images, if taken up by producers of mass audience texts, could help to 'demystify' dementia and mitigate some of the dread associated with it (Devlin et al., 2007).

Our imploration here is not directed at producers of media texts alone, but also those who design any type of text that represents dementia or people with dementia. It is accordingly a message that can be extended to, amongst others, designers of public health information, charity text designers and the very photographers and designers who contribute images to stock banks like Getty in the first place. For clinicians, it is important to be cognisant of the constitutional power of the visual (and linguistic) discourses of dementia in shaping the public's understandings and perceptions of dementia, for a consequence of reproducing the types of stigmatising imagery we have encountered in our sample might be that the automatic response of people with dementia (and their relatives) to a diagnosis of the syndrome is one of fear, not just of dementia, but of social death and loss of self. By promoting more positive images of people 'living well' with dementia (discussed above), clinicians could contribute more positive representations of the syndrome that offer some hope, and allay some of the fear, following a dementia diagnosis.

\section{Conclusion}

This is the first study to examine the representation of any health issue in commercial stock images. In critically examining visual depictions of dementia, we have aimed to respond to 
the call for more dementia-related qualitative research (Carmody et al., 2015). We also set out to demonstrate how the use of a critical multimodal approach to analysing photographs one that aims to systematically describe the semiotic composition of images, along with the connotations and associations that such compositions engender - can help expose attending ideologies and assumptions that might otherwise remain hidden and unchallenged. Certainly, at the very least, we hope that our investigation has drawn attention to the reductive power and influence of stock photographs of dementia and aging, along with the need to see them as ideologically motivated artefacts rather than transparent reflections of reality. As with other types of photograph, stock images seek to bestow 'authenticity upon any set of appearances, however false' (Berger \& Mohr, 1982: 97) and have the ability 'to create stronger emotional and immediate cues', requiring as they do less cognitive load than non-visual resources (Rodriguez \& Dimitrova, 2011: 50). Consequently, if we are to apprehend the latent meanings buried beneath their surface (Fairclough, 1995), it is imperative not to take visuals at face value, but to critically examine the ways in which they are rhetorically, persuasively composed.

Although examining stock images does little to help us directly understand the personal experiences of people with dementia (an area of investigation that remains relatively under-researched in qualitative studies), our analysis has exposed some of the ways in which these common and taken-for-granted forms of cultural representation are able to shape public understanding of, and responses to, dementia and people living with it. Our commentary is by no means exhaustive: there are semiotic aspects of the images, and the attendant meanings arising from them, that we might have overlooked or not given full attention to. It also needs to be observed that not all viewers of the various stock photographs we have examined will necessarily 'read' them in the same way as we have: we are not claiming that our semiotic analysis is, by any means, incontrovertible, that others will unfailingly recover the same 
impressions and meanings. That said, we believe we have provided sufficient semiotic evidence with which to support our visual analyses, such that reader-viewers can appreciate and assess for themselves the ways in which we have arrived at our findings.

Finally, it needs to be pointed out that, since our focus has been on relatively decontextualized stock images, future research could build on our insights by examining how stock images contribute to the representation of dementia in their more every-day contexts of use (e.g. in newspaper articles, public health information, charity publications, and so on). Moving away from the topic of dementia, researchers could adopt the multimodal critical discourse approach used in this study - which is flexible enough to get to interrogate all kinds of multi-semiotic content - to examine the visual (and linguistic) representation of a broad range of health and illness themes and issues. Given the pervasiveness of stock images pertaining to health and wellbeing, commercial image banks provide a rich data source for doing so.

\section{Endnotes}

1. Not only does the multi-purpose nature of stock photographs make them readily transplantable into a range of different settings, but also the generic aspects of such images are liable to influence meaning and inference making in their subsequent contexts of use. Although there is not the space here to consider all the contexts of use in which this happens, the example of neuroimaging helps to illustrate the point. As we elaborate in the analysis section of this paper, brain images constitute a common kind of stock image possessing distinct formal features. When they appear in the context of newspaper articles or popular science journals (to illustrate, say, some neuroscientific report or story) they impart a scientific legitimacy that other visual means of representing scientific data, such as graphs and tables, are unable to convey 
so credibly. Indeed, the presence of a brain image in a scientific article can, in the eyes of readers, render it unquestionably accurate and reliable, even if the scientific argument accompanying it is in fact fictitious and flawed (as demonstrated by McCabe and Castel's (2008) revealing set of experiments).

Yet, at the same time, not only do brain images manipulate or fortify the context in which they appear, but they also convey meanings that are potentially absent in their original (clinical) context and reception of use. For example, a brain image inserted into the context of a media article (designed for a lay rather than expert audience) will take on certain extra significances outside of its native setting. Such a recontextualized image will tend to oversimplify the structure and workings of the brain when interpreted by general readers who, acclimatized to popular press reports on neuroscience, are liable to be influenced by reductive accounts of neurological processes (McCabe \& Castel, 2008). Indeed, the pervasive use of neuroimaging in the popular press has given rise to what Racine et al. (2005) call 'neuro-realism', the notion that the inferences communicated by brain images are inviolably apodictic, that is, 'uncritically real, objective or effective in the eyes of the public' (2005: 160).

2. For a discussion of the 'decline' of the print media in the UK, see this recent article published by the Financial Times: https://www.ft.com/content/721da364-b728-11e6-

\section{ba85-95d1533d9a62.}

3. Because of copyright restrictions, this article features illustrations rather than the original images analysed. The original images can be found by searching for the image captions on the Getty website.

4. The image captions used in this article reflect the titles of the images given on the Getty websites. 
5. Although our analysis of the kinds of dementia and aging images is critical in orientation (for what we believe to be good reasons), it is not our intention to dismiss stock images entirely. Commercial images depicting people with dementia, if used judiciously, might well have a useful educational function: they might, for instance, be useful for sensitizing health professionals with respect to recognizing and treating alterations in patient mood and affect, as well as illustrating and modelling difficulties with (mis)understanding and communication in dementia care. Images such as these, moreover, might form the starting point of discussions about personhood in dementia, raising carers' and health providers' awareness of the need for supportive therapies, family counseling, and person-centred support.

\section{Declaration of Conflicting Interests}

The author(s) declared no conflicts of interest respecting the research, authorship, and/or publication of this research paper.

\section{Acknowledgements}

We would like to thank Krysia Ellis for providing the illustrations featured in this article. We would also like to thank the three anonymous reviewers for their detailed and constructive comments.

\section{References}

Adams, F. M., \& Osgood, C. E. (1973). A Cross-Cultural Study of the Affective Meanings of Color. Journal of Cross-Cultural Psychology, 4(2), 135-156.

https://doi.org/10.1177/002202217300400201 
Archer, D., Iritani, B., Kimes, B. D., \& Barrios, M. (1983). Face-ism: Five Studies of Sex Differences in Facial Prominence. Journal of Personality and Social Psychology, 45(4), $725-735$.

http://dx.doi.org/10.1037/0022-3514.45.4.725

Ballenger, J. (2006). Self, senility, and Alzheimer's Disease in Modern America: A History. Baltimore: John Hopkins University Press.

ISBN: 9780801882760

Barthes, R. (1977). Image-Music-Text. London: Fontana.

ISBN: 9780006861355

Basting, A. D. (2009). Forget Memory: Creating Better Lives for People with Dementia.

Baltimore: John Hopkins University Press.

ISBN: 9780801892509

Beaulieu, A. (2002). Images Are Not the (Only) Truth: Brain Mapping, Visual Knowledge, and Iconoclasm. Science, Technology \& Human Values, 27(1), 53-86.

https://doi.org/10.1177/016224390202700103

Behuniak, S. (2011). The living dead? The construction of people with Alzheimer's disease as zombies. Aging and Society, 31(1), 70-92.

https://doi.org/10.1017/S0144686X10000693

Berger, J., \& J. Mohr, J. (1982). Another Way of Telling. New York: Vintage International. ISBN: 9781408864463

Berger, A. (1991). Media analysis techniques. London: Sage. ISBN: 9780803943629

Bernstein B. (1990). Class, Codes and Control, Vol. IV: The Structuring of Pedagogic Discourse. London: Routledge.

ISBN: 9780415302869 
Brookes, G. (fc). Insulin restriction, medicalisation and the Internet: A corpus-assisted study of diabulimia discourse in online support groups. Communication \& Medicine. In press.

Brookes, G., \& Harvey, K. (2015). Peddling a semiotics of fear: a critical examination of scare tactics and commercial strategies in public health promotion. Social Semiotics, 25(1), 57-80.

https://doi.org/ 10.1080/10350330.2014.988920

Brookes, G., \& Harvey, K. (2016). Opening up the NHS to market: using multimodal critical discourse analysis to examine the ongoing corporatisation of health care communication. Journal of Language and Politics, 15(3), 288-302. https://doi.org/10.1075/jlp.15.3.04bro

Brookes, G., Harvey, K., Chadborn, N., \& Dening, T. (2018). “Our biggest killer”: multimodal discourse representations of dementia in the British press. Social Semiotics, 28(3), 371-395. https://doi.org/10.1080/10350330.2017.1345111

Brookes, G., Harvey, K., \& Mullany, L. (2016). 'Off to the best start'? A multimodal critique of breast and formula feeding health promotional discourse. Gender and Language, 10(3), 340-363. https://doi.org/10.1558/genl.v10i3.32035

Burri, R. V., \& Dumit, J. (2008). Social studies of scientific imaging and visualization. In E. Hackett (Ed.), The Handbook of Science and Technology Studies (3rd edition) (pp. 297-317). Cambridge, MA: MIT Press.

ISBN: 9780262083645

Caple, H. (2013). Photojournalism: A social semiotic approach. Basingstoke: Palgrave Macmillan. 
https://doi.org/10.1057/9781137314901

Carmody, J., Traynor, V., \& Marchetti, E. (2015). Barriers to Qualitative Dementia Research: The Elephant in the Room. Qualitative Health Research, 25(7), 1013-1019. https://doi.org/ 10.1177/1049732314554099

Clare, L. (2003). Managing threats to self: awareness in early stage Alzheimer's disease. Social Science \& Medicine, 57, 1017-1029. https://doi.org/10.1016/S0277-9536(02)00476-8

Cohen, D., \& Eisdorfer, C. (2001). The Loss of Self. London: W. W. Norton and Co. ISBN: 9780393050165

Davis, D. (2004). Dementia: Sociological and philosophical constructions. Social Science \& Medicine, 58(2), 369-378. https://doi.org/10.1016/S0277-9536(03)00202-8

Dening, T., \& Sandilyan, M. (2015). Dementia: definitions and types. Nursing Standard, 29 (37), 37-42. https://doi.org/10.7748/ns.29.37.37.e9405

Devlin, E., MacAskill, S., \& Stead, M. (2007). 'We're still the same people': developing a mass media campaign to raise awareness and challenge the stigma of dementia. International Journal of Nonprofit and Voluntary Sector Marketing, 12, 47-58. https://doi.org/10.1002/nvsm.273

Downs, M., Clare, L., \& Mackenzie, J. (2006). Understandings of Dementia: Explanatory Models and Their Implications for the Person with Dementia and Therapeutic Support. In Hughes, J., Louw, S., \& Sabat, S. R. (Eds.), Dementia: Mind, Meaning and the Person (pp. 235-258). Oxford: Oxford University Press. ISBN: 9780198566144

Dumit, J. (1999). Objective Brains, Prejudicial Images. Science in Conext, 12(1), 173-201. 
https://doi.org/10.1017/S0269889700003355

Du Plessis, E. (2011) The Branded Mind: What Neuroscience Really Tells Us About the Puzzle of the Brain and the Brand. London: Kogan Page Publishers. ISBN: 978-0749461256

Eakin, P. J. (2004). What Are We Reading When We Read Autobiography? Narrative, 12(2), $121-132$. https://doi.org/10.1353/nar.2004.0004

Fairclough, N. (1989). Language and Power ( $3^{\text {rd }}$ edition, 2014). London: Longman. ISBN: 9780582414839

Fairclough, N. (1995). Critical Discourse Analysis: The Critical Study of Language (2 ${ }^{\text {nd }}$ edition, 2010). London: Longman.

ISBN: 9781138226999

Fairclough, N. (2003). Analysing Discourse: Textual Analysis for Social Research. London: Routledge. ISBN: 978-0415258937

Fontana, A., \& Smith, R. W. (1989). Alzheimer's Disease Victims: The "Unbecoming” of Self and the Normalization of Competence. Sociological Perspectives, 32(1), 35-46. https://doi.org/10.2307/1389006

Frosh, P. (2008). Stock Photography. In Donsbach, W. (Ed.), The International Encyclopedia of Communication (Online), London: Blackwell. https://doi.org/10.1002/9781405186407.wbiecs104

Galasiński, D. (2008). Men's Discourses of Depression. Basingstoke: Palgrave Macmillan. https://doi.org/10.1057/9780230227620

Galasiński, D. (2017). Discourses of Men's Suicide Notes: A Qualitative Analysis. London: Bloomsbury. 
ISBN: 9781350005730

Galtung, J., \& Ruge, M. (1965). The structure of foreign news: The presentation of the Congo, Cuba and Cyprus crises in four Norwegian newspapers. Journal of Peace Research, 2(1), 64-90.

https://doi.org/10.1177/002234336500200104

Getty Images. (2018). (Website). Accessed January 2018. URL:

\section{https://www.gettyimages.co.uk/}

Gove, D., \& Rohra, H. (2014). Empowering people with dementia. In Bamford, S., Holley Moore, G. \& Watson, J. (Eds.), New Perspectives and Approaches to Understanding Dementia and Stigma (pp. 34-37), London: International Longevity Centre UK. URL: https://ilcuk.org.uk/wp-content/uploads/2018/10/Compendium-Dementia.pdf

Gwyn, R. (2002). Communicating Health and Illness. London: Sage. https://doi.org/9780761964759

Harman, G., \& Clare, L. (2006) Illness Representations and Lived Experience in Early-Stage Dementia. Qualitative Health Research, 16(4), 484-502. https://doi.org/10.1177/1049732306286851

Harrison, B. (2002). Seeing health and illness worlds - using visual methodologies in a sociology of health and illness: a methodological review. Sociology of Health and Illness, 24(6), 856-872.

https://doi.org/10.1111/1467-9566.00322

Harvey, K. (2012). Disclosures of depression: using corpus linguistics methods to interrogate young people's online health concerns. International Journal of Corpus Linguistics, 17(3), 349-379. https://doi.org/10.1075/ijcl.17.3.03har 
Harvey, K. (2013). Medicalisation, pharmaceutical promotion and the Internet: a critical multimodal discourse analysis of hair loss websites. Social Semiotics, 23(5), 691-714. https://doi.org/10.1080/10350330.2013.777596

Johnson, J., \& Bytheway, B. (1997). Illustrating care: images of care relationships with older people. In A. Jamieson (Ed.), Critical approaches to aging and later life (pp. 132 142). Buckingham: Open University Press.

ISBN: 978-0335197255

Kitwood, T. (1997). Dementia Reconsidered: The Person Comes First. Berkshire: Open University Press.

ISBN: 978-0335198559

Kontos, P. (2006). Embodied selfhood: An ethnographic exploration of Alzheimer's disease. In L. Cohen \& A. Leibing (Eds.), Thinking about dementia: culture, loss, and the anthropology of senility (pp. 195-217). New Brunswick, NJ: Rutgers University Press.

ISBN: 978-0813538037

Koteyko, N. (2014). Critical studies of health and illness discourses. In C. Hart \& P. Cap (Eds.), Contemporary Critical Discourse Studies (pp. 545-559). London: Continuum. ISBN: 9781441141637

Koteyko, N., \& Nerlich, B. (2007). Multimodal Discourse Analysis of Probiotic Web Advertising. The International Journal of Language, Society and Culture, 23, 20-31. https://doi.org/ 10.1.1.544.2585\&rep=rep1\&type=pdf

Kress, G. (2010). Multimodality: a social semiotic approach to contemporary communication. London: Routledge.

ISBN: 9780415320610 
Kress, G. \& van Leeuwen, T. (2001). Multimodal Discourse: The Modes and Media of Contemporary Communication. London: Arnold.

ISBN: 9780340608777

Kress, G., \& van Leeuwen, T. (1996). Reading Images: The Grammar of Visual Design (2 ${ }^{\text {nd }}$ edition, 2006). London: Routledge.

ISBN: 9780415106009

Lakoff, G., \& Johnson, M. (2003). Metaphors We Live By ( $2^{\text {nd }}$ edition). Chicago: University of Chicago Press.

ISBN: 9780226468013

Ledin, P. \& Machin, D. (2018). Doing Visual Analysis: From Theory to Practice. London: Sage.

ISBN: 9781526418067

Lock, M. (2013). The Alzheimer Conundrum: Entanglements of Dementia and Aging.

Princeton, NJ: Princeton University Press.

ISBN: 9780691168470

Lupton, D. (1992). Discourse analysis: a new methodology for understanding the ideologies of health and illness. Australian Journal of Public Health, 16, 145-150. https://doi.org/10.1111/j.1753-6405.1992.tb00043.x

McCabe, D., \& Castel, A. (2008). Seeing is believing: The effect of brain images on Judgements of scientific reasoning. Cognition, 107, 343-352. https://doi.org/10.1016/j.cognition.2007.07.017

McGovern, J. (2011). Couple Meaning-Making and Dementia: Challenges to the Deficit Model. Journal of Gerontological Social Work, 54(7), 678-690. https://doi.org/10.1080/01634372.2011.593021 
Machin, D. (2004). Building the World's Visual Language: The Increasing Global Importance of Image Banks in Corporate Media. Visual Communication, 3(3), 316 336.

https://doi.org/10.1177/1470357204045785

Machin, D. (2007). Introduction to Multimodal Analysis. London: Bloomsbury. ISBN: 9780340929384

Machin, D. (2013). What is multimodal critical discourse studies? Critical Discourse Studies, $10(4), 347-355$. https://doi.org/10.1080/17405904.2013.813770

Machin, D., \& Mayr, A. (2012). How to do Critical Discourse Analysis. London: Sage. ISBN: 9780857028921

Machin, D., \& Niblock, S. (2006). News Production: Theory and Practice. London Routledge.

ISBN: 9780415371414

Machin, D. \& Polzer, L. (2015). Visual Journalism. Basingstoke: Palgrave Macmillan. ISBN: 9780230360211

Machin, D., \& van Leeuwen, T. (2007). Global Media Discourse: A Critical Introduction. London: Routledge. ISBN: 9781134240913

Martin, J. R., \& Wodak, R. (2003). Introduction. In J. R. Martin \& R. Wodak (Eds.), Re/reading the past: Critical and functional perspectives on time and value (pp. 1 18). Amsterdam and Philadelphia: John Benjamins.

ISBN: 9789027226983

Martin, W. (2015). Visual methods in aging research. In J. Twigg \& W. Martin (Eds.), Routledge Handbook of Cultural Gerontology (pp. 93-104). London: Routledge. 
ISBN: 9780415631143

Mitchell, W. J. T. (2015). Image Science: Iconology, Visual Culture, and Media Aesthetics. University of Chicago Press.

ISBN: 9780226565842

Moran, J. (2001). Aging and identity in dementia narratives. Cultural Values, 5(2), 245-260. https://doi.org/ 10.1080/14797580109367230

Mulderrig, J. (2018). Multimodal strategies of emotional governance: a critical analysis of 'nudge' tactics in health policy. Critical Discourse Studies, 15(1), 39-67. https://doi.org/10.1080/17405904.2017.1382381

Newton, J. (2013). The burden of visual truth: The role of photojournalism in mediating reality. London: Routledge.

ISBN: 9781135665654

Phinney, A., \& Chesla, C. A. (2003). The lived body in dementia. Journal of Aging Studies, 17(3), 283-299. https://doi.org/10.1016/S0890-4065(03)00029-X

Pickersgill, M. (2013). The Social Life of the Brain: Neuroscience in Society. Current Sociology, 61(3), 322-340. https://doi.org/10.1177/0011392113476464

Racine, E., Bar-Illan, O., \& Illes, J. (2005). fMRI in the public eye. Nature Reviews Neuroscience, 6, 159-164.

https://doi.org/10.1038/nrn1609

Rahman, S. (2014). Living Well with Dementia: The Importance of the Person and the Environment for Wellbeing. London: CRC Press.

ISBN: 978-1908911971 
Reisigl, M., \& Wodak, R. (2001). Discourse and Discrimination: Rhetorics of Racism and Antisemitism. London: Routledge.

ISBN: 9780415231497

Rodriguez, L., \& Dimitrova, D. V. (2011). The levels of visual framing. Journal of Visual Literacy, 30(1), 48-65.

https://doi.org/10.1080/23796529.2011.11674684

Sabat, S. R., (2001). The Experience of Alzheimer's Disease: Life Through a Tangled Veil. Oxford and Malden, MA: Blackwell.

ISBN: 978-0631216667

Sabat, S.R. (2006). Mind, meaning, and personhood in dementia: the effects of positioning. In J.C. Hughes, S. Louw, \& S.R. Sabat (Eds.), Dementia: Mind, Meaning, and the Person (pp. 287-302). Oxford: Oxford University Press.

ISBN: 978-0198566151

Sabat, S. R. (2014). A Bio-Psycho-Social Approach to Dementia. In M. Downs \& B. Bowers (Eds.), Excellence in Dementia Care: Research Into Practice (2nd edition) (pp. 107 121). New York: Open University Press/McGraw Hill.

ISBN: 978-0335223756

Sabat, S. R. (2018). Alzheimer's Disease \& Dementia: What Everyone Needs to Know. New York: Oxford University Press.

ISBN: 978-0190603113

Sabat, S. R., \& Harré, R. (1992). The Construction and Deconstruction of Self in Alzheimer's Disease. Aging and Society, 12, 443-461. https://doi.org/10.1017/S0144686X00005262

Segal, J. (1998). Writing and medicine: Text and context. In R. Spilka (Ed.), Writing in the workplace (pp.84-97), Carbondale: Southern Illinois University Press. 
ISBN: 780809321858

Sontag, S. (1977). On Photography. New York: Farrar, Straus and Giroux. ISBN: 0-374-22626-1.

Stites, S. D., Rubright, J. D., \& Karlawish, J. (2018). What features of stigma do the public most commonly attribute to Alzheimer's disease dementia? Results of a survey of the U.S. general public. Azlherimer's \& Dementia. Online first. Available: https://alzcnfl.files.wordpress.com/2018/04/stigma_survey_march2018.pdf. https://doi.org/10.1016/j.jalz.2018.01.006

Swaffer, K. (2014). Dementia: Stigma, Language, and Dementia-friendly. Dementia, 13(6), 709-716. https://doi.org/10.1177/1471301214548143

Swinnen, A., \& Schweda, M. (2015). Popularizing dementia. Public expressions and representations of forgetfulness. In A. Swinnen \& M. Schweda (Eds.), Popularizing Dementia: Public Expressions and Representations of Forgetfulness (pp. 9-22). Bielefeld: transcript Verlag. ISBN: 9783837627107

Tallis, R. (2003). The Hand: A Philosophical Inquiry into Human Being. Edinburgh: Edinburgh University Press. ISBN: 978-0748617388

Taylor, P. (1992). War and the Media: Propaganda and Persuasion in the Gulf War. Manchester: Manchester University Press. ISBN: 9780719037542

Thompson, R. (2012). Looking healthy: visualizing mental health and illness online. Visual Communication, 11(4), 395-420. https://doi.org/10.1177/1470357212453978 
van Dijck, J. (2006). Picturizing Science: The Science Documentary as Multimedia Spectacle. International Journal of Cultural Studies, 9(1), 5-24. https://doi.org/10.1177/1367877906061162

van Dijk, T. A. (2001). Critical Discourse Analysis. In D. Tannen, D. Schiffrin, \& H. Hamilton (Eds.), Handbook of Discourse Analysis (pp. 357-371). Oxford: Blackwell. ISBN: 978-0631205968

Van Gorp, B., \& Vercruysse, T. (2012). Frames and Counter-Frames Giving Meaning to Dementia: A Framing Analysis of Media Content. Social Science \& Medicine, 74(8), $1274-1281$. https://doi.org/10.1016/j.socscimed.2011.12.045

Van Leeuwen, T. J. (1999). Speech, Music, Sound. Basingstoke: Palgrave Macmillan. ISBN: 9780333642894

Van Leeuwen, T. J. (2005). Introducing Social Semiotics. London \& New York: Routledge. ISBN: 9780415249430

Van Leeuwen, T. J. (2008). Discourse and Practice: New Tools for Critical Discourse Analysis. Oxford: Oxford University Press.

ISBN: 978-0195323313

Van Leeuwen, T. J. (2011). The Language of Colour: An Introduction. London \& New York: Routledge.

ISBN: 978-0415495387

Werner, P. (2003). Knowledge about symptoms of Alzheimer's disease: Correlates and relationship to help-seeking behaviour. International Journal of Geriatric Psychiatry, 18(11), 1029-1036. https://doi.org/10.1002/gps.1011

Wodak, R. (1996). Disorders of Discourse. London: Longman. 
ISBN: 9780582099562

Wodak, R. (1997). Critical discourse analysis and the study of doctor-patient interaction. In B.-L. Gunnarsson, P. Linell, \& B. Nordberg (Eds.), The Construction of Professional Discourse (pp. 173-200). London: Longman.

ISBN: 9780582259416

World Health Organisation (WHO). (2017). Dementia: Fact Sheet. Accessed July 2018. http://www.who.int/mediacentre/factsheets/fs362/en/.

Zeilig, H. (2014). Dementia as a Cultural Metaphor. The Gerontologist, 54(2), 258-267. https://doi.org/10.1093/geront/gns203

Zimmermann, M. (2017). Alzheimer's disease metaphors as mirror and lens to the stigma of dementia. Literature and Medicine, 35(1), 71-97. https://doi.org/10.1353/lm.2017.0003

Ziółkowska, J. (2009). Positions in Doctors' Questions During Psychiatric Interviews. Qualitative Health Research, 19(11), 1621-1631. https://doi.org/10.1177/1049732309350685 